NASA Technical Memorandum 100888

\title{
Vibration and Control of Flexible Rotor Supported by Magnetic Bearings
}

\author{
(NASA-TH-100888) VIBRATICN AND CCNTROL OF \\ FIEXIBLE BOTCE SCEFCBIED BY LEEEIIC \\ EFARIIIGS (NASA) $23 \mathrm{~F}$ CSCL 13E \\ N88-23977 \\ Unclas \\ G3/37 0147000
}

Kenzou Nonami

Lewis Research Center

Cleveland, Ohio

Prepared for the

First International Conference on Magnetic Bearings

cosponsored by the Swiss Federal Institute of Technology (ETH) and

the Swiss Society of Microtechnics (SGMT)

Zurich, Switzerland, June 6-8, 1988 


\title{
VIBRATION AND CONTROL OF FLEXIBLE ROTOR SUPPORTED BY MAGNETIC BEARINGS
}

\author{
Kenzou Nonami * \\ National Aeronautics and Space Administration \\ Lewis Research Center \\ Cleveiand Onio 44135
}

\section{INTRODUCTION}

Many papers have been written on magnetic bearings. These papers are divided into two categories: One is the use of magnetic bearings taking the place of contact bearings, and the other is the use of noncontact actuators for active vibration control. These catergories are combined in applications. The research on using magnetic bearings in place of contact bearings has been going on for years. As early as 1842 it was known that magnetic bearings should have at least one direction actively controlled (ref. 1). For the last century and a half there has been a great deal of research and development. Magnetic bearings have been used mainly in experiments and in aircraft and missile inertial guidance control. However, these bearings are now coming into use in the industrial world (ref. 2) for turbo-molecular pumps (ref. 3), machine tool spindles, etc. Although these magnetic bearings are for rigid rotors (refs. 4 to 6 ), they recently have been used with flexible rotors (refs. 7 to 9). In such applications, the magnetic bearings suppress unbalance vibration. Many papers have been published on this subject (refs. 10 to 16).

This paper is concerned with active vibration control of flexible rotors supported by magnetic bearings. Using a finite-element method for the mathematical model of a flexible rotor, the author has formulated the eigenvalue problem taking into account the interaction between the mechanical system of a flexible rotor and the electrical system of magnetic bearings and a controller. However, for the sake of simplicity, gyroscopic effects are disregarded herein. It is possible to adapt this formulation to a general flexible rotor - magnetic bearing system. Controllability with and without collocation sensors and actuators located at the same distance along the rotor axis is discussed for the higher order flexible modes of the test rig. In conclusion, the author has proposed that it is necessary to add new active control loops for the higher flexible modes even in the case of collocation. "It is then possible to stabilize for the case of uncollocation by means of this method.

\section{ANALYSIS OF ROTOR - MAGNETIC BEARINGS SYSTEM FOR RIGID ROTOR}

\section{Basic Equation}

This paper deals with a radial-type magnetic bearing system. Figure 1 shows four assembled electromagnets. The whole system is shown in figure 2 where the flexible rotor shown is rigid. We have the following assumptions:

(1) The attractive forces are proportional to the square of the coil current.

(2) Both electromagnetic bearings have the same characteristics.

*National Research Council - NASA Research Associate; on leave from Chiba University, 1-33 Yayoi-cho, Chiba 260 Japan. 
(3), The induced voltages of electromagnets are ignored.

(4) The coil inductances are independent of frequency and gap length and are constant.

(5) This system is uncoupled between the $x$ and $y$ directions.

(6) Only small vibrations near equilibrium are considered.

(7) The rotor mass is concentrated at the bearing. magnet:

Under these conditions, we obtain the following equation for one electro-

$$
E=L \frac{d I}{d t}+R I
$$

where $E$ is the coil input voltage, $\dot{L}$ the coil inductance, $R$ the coil resistance, and I the coil current. The attractive force of an electromagnet can generally be given by

$$
P=\frac{\mu_{0} A N^{2} I^{2}}{H^{2}}
$$

where $P$ is the attractive force, $\mu_{0}$ the permeability, $A$ the face area, $N$ the number of, winding turns, and $H$ the gap length. From the standpoint of small. vibration near equilibrium, P, H, and I are given by

$$
\left.\begin{array}{l}
P=p_{0}+p \\
I=i_{0}+i \\
G=h_{0}+h
\end{array}\right\}
$$

where $p_{0}$ is the steady-state attractive force, io the steady-state current, $h_{0}$ the steady-state gap length, $p$ the control attractive force, $i$ the control current, and $h$ the control gap length. Using the Taylor series expansion for small values of $i$ and $h$ and assuming $i_{0} \gg i$ and $h_{0}>i h$, we can finally get the following attractive control force in linear terms:

$$
p=2 p_{0}\left(\frac{i}{i_{0}}-\frac{h}{h_{0}}\right)
$$

The four control attractive forces $p_{1}, p_{2}, p_{3}$, and $p_{4}$ are shown in figure 1 . The resultant forces of the horizontal control attractive force and the vertical control attractive force are, respectively,

$$
\begin{gathered}
m \ddot{x}=p_{1}-p_{3} \\
m \ddot{y}=\left(p_{s}+p_{2}\right)-\left(p_{0}+p_{4}\right)-m g
\end{gathered}
$$


where $m$ is the half-mass of the rigid rotor and $g$ the acceleration of grav$i$ ty. Assuming that control currents to coils are $i_{3}=-i_{1}$ and $i_{4}=-i_{2}$, we have the following expressions considering equation (4):

$$
\begin{gathered}
m \ddot{x}=-4 p_{0}\left(\frac{i_{x}}{i_{0}}-\frac{x}{h_{0}}\right) \\
m \ddot{y}=-2\left(\frac{p_{s}}{i_{s}}+\frac{p_{0}}{i_{0}}\right) i_{y}+2\left(\frac{p_{s}}{h_{0}}+\frac{p_{0}}{h_{0}}\right) y
\end{gathered}
$$

where the control gap length $h$ is replaced by the displacements $x$ and $y$ from equilibrium; $m g+p_{0}$ is replaced by the steady-state attractive force $p_{S}$ and the steady-state current $i_{s}$.

The phase lead circuit shown in figure 3 is used to compensate for the time constant of electromagnets in order to maintain control at higher frequencies. Using figure 3 , we can obtain the following equation:

$$
\frac{d V}{d t}=\frac{E_{1}}{C R_{1}}-\frac{R_{1}+R_{2}}{C R_{1} R_{2}} V
$$

where the new parameter $V$ is the voltage at $R_{2}$ and $C$.

\section{State Equation and Control System}

The integral values of displacements are used as control variables to compensate for any drift from the equilibrium position. The formulas are

$$
\left.\begin{array}{l}
\alpha=\int_{0}^{t} x d t \\
\beta=\int_{0}^{t} y d t
\end{array}\right\}
$$

Replacing $E$ with $E_{1}-V$ in equation (1) (since $E=E_{1}-V$ ), we get

$$
\frac{d i}{d t}=\frac{l}{L}\left(E_{1}-V\right)-\frac{R}{L}
$$

Using equations (5) to (9), we can write the state equations as

$$
\begin{aligned}
& \{\dot{X}\}=\left[A_{X}\right]\{X\}+\{b\} u_{x} \\
& \cdot\{\dot{Y}\}=\left[A_{y}\right]\{Y\}+\{b\} u_{y}
\end{aligned}
$$

where $\left[A_{x}\right]$ is the horizontal system matrix and $\left[A_{y}\right]$ is the vertical system matrix. There are as follows: 


$$
\begin{aligned}
& \therefore \quad \therefore \quad \therefore \quad \cdots\left[\begin{array}{cccccc}
0 & 1 & 0 & 0 & 0 \\
\frac{4 p_{0}}{m h_{0}} & 0 & 0 & -\frac{4 p_{0}}{m i_{0}} & 0 \\
1 & 0 & 0 & 0 & 0 \\
1 & 0 & 0 & -\frac{R}{L} & -\frac{1}{L} \\
0 & 0 & 0 & 0 & -\frac{R_{1}+R_{2}}{C R_{1} R_{2}}
\end{array}\right] \\
& {\left[A_{y}\right]=\left[\begin{array}{ccccc}
0 & 1 & 0 & 0 & 0 \\
\frac{2}{m}\left(\frac{p_{s}}{h_{0}}+\frac{p_{0}}{h_{0}}\right) & 0 & 0 & -\frac{2}{n}\left(\frac{p_{s}}{i_{s}}+\frac{p_{0}}{i_{0}}\right) & 0 \\
1 & 0 & 0 & 0 & 0 \\
0 & 0 & 0 & -\frac{R}{L} & -\frac{1}{L} \\
0 & 0 & 0 & 0 & -\frac{R_{1}+R_{2}}{C R_{1} R_{2}}
\end{array}\right]}
\end{aligned}
$$

The state vectors $\{X\}$ and $\{Y\}$; the control vector $\{b\}$, and the control inputs $u_{x}$ and $u_{y}$ are given by

$$
\begin{aligned}
& \{x\}=\left[x, \dot{x}, \alpha, \dot{j}_{x}, v_{x}\right]^{\top} \\
& \{Y\}=\left[y, \dot{y}, \beta, i_{y}, V_{y}\right]^{\top} \\
& \{\mathrm{b}\}=\left[0,0,0, \frac{1}{\mathrm{~L}}, \frac{1}{\mathrm{CR}}\right]^{\top} \\
& \left.\begin{array}{l}
u_{x}=E_{1 x} \\
u_{y}^{\prime}=E_{1 y}
\end{array}\right\}
\end{aligned}
$$

where $T$ means transpose. The control input voltages $E_{1 x}$ and $E_{1 y}$ are given by combining the feedback with displacements, velocities, and integrations of displacements. 
Therefore, the output feedback control system of PID type is

$$
\left.\begin{array}{l}
u_{x}=-:\left\{F_{x}\right\}\{X\} \\
u_{y}=-\left\{F_{y}\right\}\{Y\}
\end{array}\right\}
$$

where

$$
\left.\begin{array}{l}
\left\{F_{x}\right\}=\left[f_{1 x}, f_{2 x}, f_{3 x}, 0,0\right] \\
\left\{F_{y}\right\}=\left[f_{1 y}, f_{2 y}, f_{3 y}, 0,0\right]
\end{array}\right\}
$$

Elements of $\left\{F_{x}\right\}$ and $\left\{F_{y}\right\}$ are feedback gains.

\section{Characteristic Equation}

Substituting equation (18) into equations (10) and (11) and taking the Laplace transformation give the characteristic equation in the horizontal direction as

$$
s^{5}+a_{1} s^{4}+a_{2} s^{3}+a_{3} s^{2}+a_{4} s+a_{5}=0
$$

where

$$
\begin{aligned}
& a_{1}=\frac{R}{L}+Q \\
& a_{2}=\frac{Q R}{L}-\frac{4 p_{0} f_{2}}{m i}-\frac{4 p_{0}}{m h_{0}} \\
& a_{3}=-\frac{4 p_{0} f_{2} Q}{m \dot{i}_{0} L}-\frac{4 p_{0} f_{1}}{m \dot{i}_{0} L}-\frac{4 p_{0} R}{m h_{0} L}-\frac{4 p_{0} Q}{m h_{0}}+\frac{4 p_{0} f_{2}}{m i_{0} L C R_{1}} \\
& a_{4}=-\frac{4 p_{0} f_{3}}{m \dot{j}_{0} L}-\frac{4 p_{0} f_{1} Q}{m i_{0} L}-\frac{4 p_{0} R Q}{m h_{0} L}+\frac{4 p_{0} f_{1}}{m_{0} L C R_{1}} \\
& a_{5}=-\frac{4 p_{0} f_{3} Q}{m i_{0} L}+\frac{4 p_{0} f_{3}}{m i_{0} L C R_{1}} \\
& Q=\frac{R_{1}+R_{2}}{C R_{1} R_{2}}
\end{aligned}
$$

Likewise, in the vertical direction,

$$
s^{5}+b_{1} s^{4}+b_{2} s^{3}+b_{3} s^{2}+b_{4} s+b_{5}=0
$$


where

$$
\begin{aligned}
& b_{1}=\frac{R}{L}+Q \\
& b_{2}=\frac{f_{2} B}{L}+\frac{R Q}{L}-A \\
& b_{3}=\frac{f_{1} B}{L}+\frac{f_{2} B Q}{L}-\frac{A R}{L}-\frac{f_{2} B}{L C R_{1}}-A Q \\
& b_{4}=\frac{f_{3} B}{L}+\frac{f_{1} B Q}{L}-\frac{A R Q}{L}-\frac{f_{1} B}{L C R_{1}} \\
& b_{5}=\frac{f_{3^{B Q}}}{L}-\frac{f_{3^{B}}}{L C R_{1}} \\
& A=\frac{2}{m}\left(\frac{p_{s}}{h_{0}}+\frac{p_{0}}{h_{0}}\right) \\
& B=-\frac{2}{m}\left(\frac{p_{s}}{i_{s}}+\frac{p_{0}}{i_{0}}\right) \\
& Q=\frac{R_{1}+R_{2}}{C R_{1} R_{2}}
\end{aligned}
$$

The subscripts $x$ and $y$ of feedback gains are omitted after this section. The stability criterion of feedback gains $f_{1}, f_{2}$, and $f_{3}$ is decided by equations (20) and (21).

\section{ANALYSIS OF ROTOR - MAGNETIC BEARING SYSTEM FOR FLEXIBLE ROTOR}

The mathematical model for this flexible rotor is given by using a finite element method:

$$
[M]\{\ddot{q}\}+[G]\{\dot{q}\}+[K]\{q\}=\{0\}
$$

where $[M],[G]$, and $[K]$ are the mass, gyroscopic, and stiffness matrices, respectively. We assume $[G]=0$ for simplicity. This flexible rotor is now divided into six elements as shown in figure:2, and the state values are set at $x_{i}$ and $\theta_{i}$ at each station. [M] and [K] become $14 \times 14$ matrices and $\{X\}$ vector has a length of 14 in this case. The flexible rotor is supported by magnetic bearings at stations 2 and 6 , and sensors are located at stations 1 and 7 . From these results, the formulations in the horizontal direction of the left magnetic bearing shown in figure 2 are defined by 


$$
\begin{array}{r}
u_{x \ell}=\frac{4 P_{\ell}}{H_{\ell}} x_{2}-\frac{4 P_{\ell}}{I_{\ell}} i_{x \ell} \\
E_{1 \times \ell}-v_{x \ell}=L \frac{d i_{x \ell}}{d t}+R i_{x \ell} \\
v_{x \ell}=\frac{E_{1 \times \ell}}{C R_{1}}-\frac{R_{1}}{C R_{1} R_{2}} V_{x \ell} \\
E_{1 \times \ell}=-f_{1 \ell} x_{1}-f_{2 \ell} \dot{x}_{1}-f_{3 \ell}{ }^{\alpha} \ell
\end{array}
$$

where the force $u_{x \ell}$ acts on station 2, and the subscript $\ell$ indicates the left magnetic bearing. The steady-state values $p_{0}, h_{0}$, and io are replaced by $\mathrm{P}_{\ell}, \mathrm{H}_{\ell}$, and $\mathrm{I}_{\ell}$. The expressions are derived about the right magnetic bearing in the same manner. Combining equations (22) and (23), we can obtain the 34 th order state equation as shown in equation (24):

[See page 8]

7 


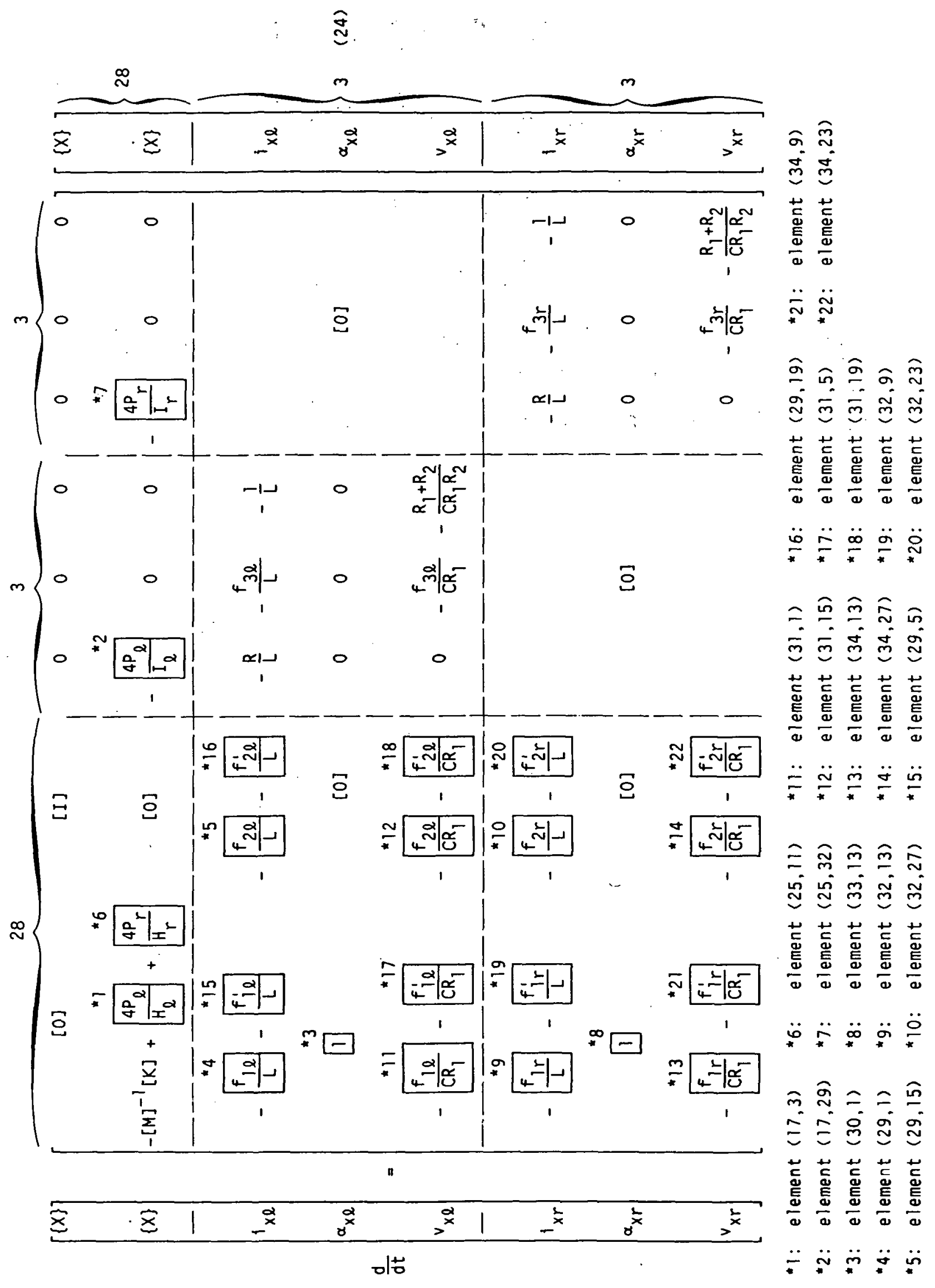


where the subscript $r$ means the right magnetic bearing. In addition, $f_{i l}^{\prime}$, $f_{2 l}^{\prime}$, $f_{1 r}^{\prime}$, and $f_{2 r}$. show feedback gains added for active vibration control loops for higher modes. Similarly, we get almost the same equation for the vertical direction. Equation (24) is systematically formulated for a general flexible rotor with magnetic bearings. We can design the control system by solving the eigenvalue problem of equation. (24).

\section{EXPERIMENTS}

Test Rig

The laboratory test rotor is shown schematically in figure 2 . Figure 4 is a photograph of the test rig. The flexible shaft, which is a 10-mm-diameter drill rod that is $1000 \mathrm{~mm}$ long, has five disks with masses as indicated in figure 2. The total mass of the flexible rotor is about $3.3 \mathrm{~kg}$. Two of the disks are used for magnetic bearings and two others are used for sensors - i.e., the bearings and sensors are not collocated. The rotor is supported by two magnetic bearings with a bearing span length of $680 \mathrm{~mm}$. The shaft is connected to the driving motor by a flexible coupling. This is a radial magnetic bearing system with four degrees of freedom only because the radial directions are noncontacting. "The gap between the electromagnets and the disk is about $2.0 \mathrm{~mm}$. The backup bearings protect in an emergency when the amplitudes exceed $1.0 \mathrm{~mm}$. The shaft displacements, which are measured by gap sensors of the eddy current type, are measured as close as possible to the magnetic bearings. These signals are the inputs for the analog controller. The analog controller consists of proportional, "differential, and integral circuits, the phase lead.circuit, and some filters. The control signals from the analog controllers are supplied to the electromagnets through servoamplifiers.

\section{Experiments for Rigid Rotor}

At low frequencies the test rig rotor can be considered rigid. Figure 5 : shows the three-dimensional stability criterion chart for the horizontal direction based on the Hurwitz's criterion of equation (20). Figure 6 is for the vertical direction. It is clear from the results that feedback gains $f_{1}$, $f_{2}$, and $f_{3}$ should be negative. The stability improves when the absolute values of feedback gains become large; however, the stability region becomes narrow when $\left|f_{1}\right|$ is large.

Figure 7 shows the root loci for different feedback gains. The calculations shown were done on the basis of feedback gains at the intersection points of the solid line, the dotted lines, and the dot-dash lines. In the case of the solid line $\left(f_{p}\right)$, the system becomes unstable because the pole which goes to the right and up passes over the imaginary axis to the other side. This corresponds to the case in. which the stability iregion becomes narrow when $\left|f_{1}\right|$ becomes large (see figs. 5 and 6 ). In the case of the dashed line $\left(f_{2}\right)$, the system does not become unstable though one pole goes toward the origin. Figure 7 shows that the sensitivity for variation of $f_{3}$ is very low when the behaviors of real roots are omitted. The static spring constants were measured with the rotor floating and the system statically stable. This was done by measuring the deflection of the shaft ard the force' of the tension spring balance after attaching the spring:balance to the end of the shaft. The results 
are shown in figure 8 . The force vs. deflection curves for these magnetic bearings are linear over the range of interest. The spring constant used in the following experiments is about $1.5 \times 10^{4} \mathrm{~N} / \mathrm{m}$.

\section{Experiments For Flexible Rotor}

Critical speed map. - Figure 9 shows the critical speed map of the rotor model shown in figure 2. In the case shown, both stations 2 and 6 are supported by the equivalent spring $K$. For zero bearing stiffness, there are two rigid modes at $0 \mathrm{~Hz}$, the first bending mode at $20 \mathrm{~Hz}$, the second at $86 \mathrm{~Hz}$, and the third at $130 \mathrm{~Hz}$. The computed free-free data have good agreement with the measured free-free test data shown in figure 10 . From this, it seems that the mathematical model is correct. The actual critical speeds are estimated (shown by dot-dash line in fig. 9) using the measured spring constant.

Frequency response of flexible rotor - magnetic bearing system. - Figure 11 shows the measured frequency responses of the FFT analyzer based on an impulse response using the same conditions as in figure 8 . Figure 12 shows measured mode shapes. The first mode at $10.40 \mathrm{~Hz}$ is omitted because it is similar to the second mode. The modal damping ratio at the first mode was $\zeta=15.04$ percent. The measured critical speeds up to the fifth in figures 11 and 12 coincide with the computed critical speeds shown in figure 9. The resonance peaks from the first through the third are not clearly recognized because of their high modal damping ratios as shown in figure 12 .

Eigenvalue analysis. - In this section, we determine the eigenvalues by using equation (24). Table I lists the eigenvalues with collocation in the ideal case, and table II shows the eigenvalues without collocation in the case of this experiment. Only complex eigenvalues are listed in the tables and the real roots are omitted. The parameters and feedback gains used for the eigenvalue analysis are the same as those used in the previous section. The results in table II almost coincide with the results of the critical speeds shown in figures 9 and 11 . The fourth mode is unstable in table II. The measured modal damping ratio at $123.13 \mathrm{~Hz}$ (as shown in fig. 12) is too small. Moreover, we cannot pass the fourth critical speed (as shown in fig. 13) because the amplitudes at locations near the magnetic bearings are growing at speeds greater than $5500 \mathrm{rpm}$. Therefore, the results of the eigenvalue analysis of equation (24) are reasonable. It is possible to design the control system of a flexible rotor magnetic bearing system by using the eigenvalue analysis of equation (24). It is clear that every mode is stable with collocation. However, the roots of the higher order modes approach the imaginary axis as shown in table I. Table III shows the improvement of the higher modes with collocations in addition to new velocity feedback loops. The difficulty of passing the higher order critical speeds with collocation is a very important result. Namely, it points out that the usual design method for a rigid rotor has a natural limitation for control of flexible modes. New active control loops are needed for the higher flexible modes even with collocation.

Unbalance response. - Figure 13 shows the unbalance responses for this experiment for the conditions indicated previously. The results show that both the horizontal and the vertical responses have similar characteristics. There are only low amplitude resonances up to $5500 \mathrm{rpm}$. The rotor should have passed the fourth critical speed by $5500 \mathrm{rpm}$ since the fourth critical speed exists at $84 \mathrm{~Hz}, 5040 \mathrm{rpm}$ as shown in figure 12. Some results indicate that this is caused by gyroscopic effects. 
Active vibration control. - Improving the damping characteristics at the fourth mode is needed in addition to considering the velocity feedbacks $f_{2 l}^{\prime}$ and $f_{2 r}^{\prime}$. Namely, the vibration velocities measured at locations 3 and 5 are used as the control inputs at locations 2 and 6 . The results of the eigenvalue analysis for this are shown in figure 14. The measured frequency responses by an FFT analyzer are shown in figures $11(b)$ and (d). The analys is and experiments show that the characteristics of the fourth mode are improved by active velocity feedback loops. It is possible to pass the fourth critical speed if the dynamic characteristics are as shown in figures $11(b)$ and (d). However, it is impossible to pass the fourth critical speed in the actual test rig because of gyroscopic effects. We must design the active vibration control system taking into account the gyroscopic effects of matrix [G] in equation (22). The higher order critical speeds can be passed if the flexible rotor - magnetic bearing control system is designed using the stable eigenvalues of equation (24) that take into account gyroscopic effects.

\section{CONCLUSIONS}

This paper deals with vibration problems and control methods without gyroscopic effects for a flexible rotor supported by radial magnetic bearings with a four-degree-of-freedom system. The conclusions obtained are as follows:

(1) The eigenvalue problem, taking into account the interaction between the mechanical system of a flexible rotor and the electrical system of magnetic bearings and the controller, can be formulated as shown herein. The control system of a flexible rotor - magnetic bearing system was designed by an eigenvalue analysis.

(2) If the control system is designed for a rigid rotor, the flexible modes do not become unstable with collocation.

(3) New active control loops must be added for the higher flexible modes even with collocation because the damping characteristics degenerate for the higher order modes. It is possible to stabilize for the case of no collocation by means of this method.

(4) It is not possible to pass the critical speed in the actual test rig even if frequency responses by a FFT analyzer are satisfactory mainly because of gyroscopic effects with rotation.

\section{REFERENCES}

1. Habermann, H.; and Brunet, M.: The Active Magnetic Bearing Enables Optimum Damping of Flexible Rotor. ASME Paper 84-GT-117, 1984.

2. Habermann, H.; and Liard, G.: An Active Magnetic Bearing System. Tribology Int. 13 (1980) 85-89.

3. Foster, E.G.; Kulle, V.; and Peterson, R.A.: The Application of Active Magnetic Bearings to a Natural Gas Pipeline Compressor. ASME Paper $86-G T-61,1986$. 
4. Matsumura, F.; Kaobayashi, H.; and Akiyama, Y.: Fundamental Equation for Horizontal Shaft Magnetic Bearing and It.s Control System Design. Electr. Eng.Jjpn., 101 (3) (1981) 123-130.

5. Matsumura, F.: System and Control, 26 (1982), 209 (in Japanese).

6. Higuchi, T.; and Mizuno, T.: Control System Design for Totally Active DC-Type Magnetic Bearings - Structures of the Optimal Regulator for Systems with Gyroscopic Coupling. Trans. Soc. Instrum. Control Eng., 18 (1982), 507-513 (in Japanese).

7. Allaire, P.E.; Humphris, R.R.; and Kelm, R.D.: Dynamics of a Flexible Rotor in Magnetic Bearings. Rotordynamic Instability Problems in HighPerformance Turbomachinery, NASA CP-2443, Washington, D.C.: NASA, 1986, pp. 419-430.

8. Matsushita, 0., et a 1.: Proceedings International Conference on Rotordynamics (1986), 421.

9. Salm, J.R.: Active Electromagnetic Suspension of an Elastic Rotor: Modeling Control and Experimental Results. Rotating Machinery Dynamics. Vo1.1, A. Muszynska and J.C. Simonis (eds.) New York: ASME, 1987, pp. 141-149.

10. Schweitzer, G.: Dynamics of Rotors. F.I. Niordson (ed.) New York: Springer-Verlag, 1975, pp. 472.

11. Nikolajsen, J.L.; Holmes, R.; and Gondhalekar, V.: Investigation of an Electromagnetic Damper for Vibration Control of a Transmission Shaft.

Proc. Inst. Mech. Eng., 193 (1979), 331-336.

12. Ulbrich, H.; and Anton, E.: Inst. Mech. Eng. Conf. C299/84 (1984) 543.

13. Anton, E.; and Ulbrich, H.: Active Control of Vibrations in the Case of Asymmetrical High-Speed Rotors by Using Magnetic Bearings. J. Vibration Acoustics. Stress and Reliability in Design, 107 (1985) 410-415.

14. Salm, J.R.; and Schweitzer, G.: Inst. Mech. Eng. Conf. C277/84 (1984) 553.

15. Okada.,Y., et al.: Trans. Jpn. Soc. Mech. Eng., Vol. 52, No. 467 (1985) 1760 (in Japanese).

16. Matsushita, 0., et al.: Trans. Jpn. Soc. Mech. Eng., Vol. 53, No. 496 (1987), 2453 (in Japanese). 
TABLE I. - EIGENVẢLUES WITH COLLOCATION

\begin{tabular}{|c|c|c|}
\hline Real & Imaginary & $\begin{array}{c}\text { Frequency, } \\
\mathrm{Hz}\end{array}$ \\
\hline$-0.222730-2$ & $0.36128 \mathrm{D}+5$ & 5750.0 \\
$-.223590-1$ & $.157250+5$ & 2502.7 \\
$-.702420-1$ & $.127840+5$ & 2034.6 \\
$-.575190+0$ & $.593810+4$ & 945.1 \\
$-.897740+1$ & $.291590+4$ & 464.1 \\
$-.226300+2$ & $.206260+4$ & 328.3 \\
$-.647340+2$ & $.946920+3$ & 150.7 \\
$-.474600+2$ & $.667310+3$ & 106.2 \\
$-.82129 D+2$ & $.15805 D+3$ & 25.2 \\
$-.941460+2$ & $.152870+3$ & 24.3 \\
$-.49705 D+1$ & $.12235 D+3$ & 19.5 \\
\hline
\end{tabular}

TABLE II. - EIGENVALUES WITHOUT COLLOCATION

\begin{tabular}{|c|c|c|}
\hline Real & Imagi nary & $\begin{array}{c}\text { Frequency, } \\
\mathrm{Hz}\end{array}$ \\
\hline $0.16181 \mathrm{D}+2$ & $0.20101 \mathrm{D}+4$ & 319.9 \\
$.74842 \mathrm{D}+2$ & $.86925 \mathrm{D}+3$ & 138.3 \\
$.71604 \mathrm{D}+2$ & $.62756 \mathrm{D}+3$ & 99.9 \\
$-.11111 \mathrm{D}+3$ & $.17393 \mathrm{D}+3$ & 27.7 \\
$-.12722 \mathrm{D}+3$ & $.15032 \mathrm{D}+3$ & 23.9 \\
$-.65155 \mathrm{D}+1$ & $.10677 \mathrm{D}+3$ & 17.0 \\
\hline
\end{tabular}

TABLE III. - EIGENVALUES WITH COLLOCATION IN ADDITION TO VELOCITY FEEDBACK

\begin{tabular}{|c|r|c|}
\hline Real & Imaginary & $\begin{array}{c}\text { Frequency, } \\
\mathrm{Hz}\end{array}$ \\
\hline$-0.46911 \mathrm{D}+3$ & $0.11555 \mathrm{D}+4$ & 183.9 \\
$-.59602 \mathrm{D}+3$ & $.91103 \mathrm{D}+3$ & 145.0 \\
$-.14625 \mathrm{D}+3$ & $.36865 \mathrm{D}+3$ & 58.7 \\
$-.286290+3$ & $.34515 \mathrm{D}+3$ & 54.9 \\
$-.46764 \mathrm{D}+0$ & $.13729 \mathrm{D}+3$ & 21.9 \\
\hline
\end{tabular}




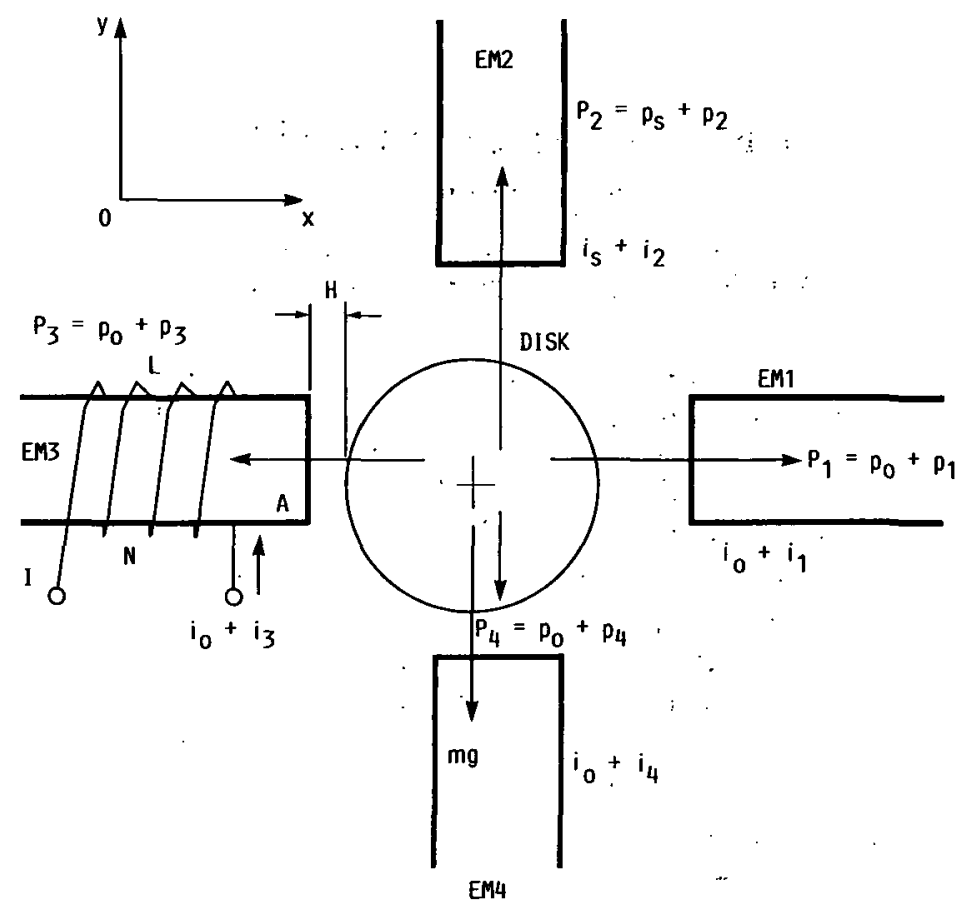

FIG. 1. - FOUR ASSEMBLED ELECTROMAGNETS.

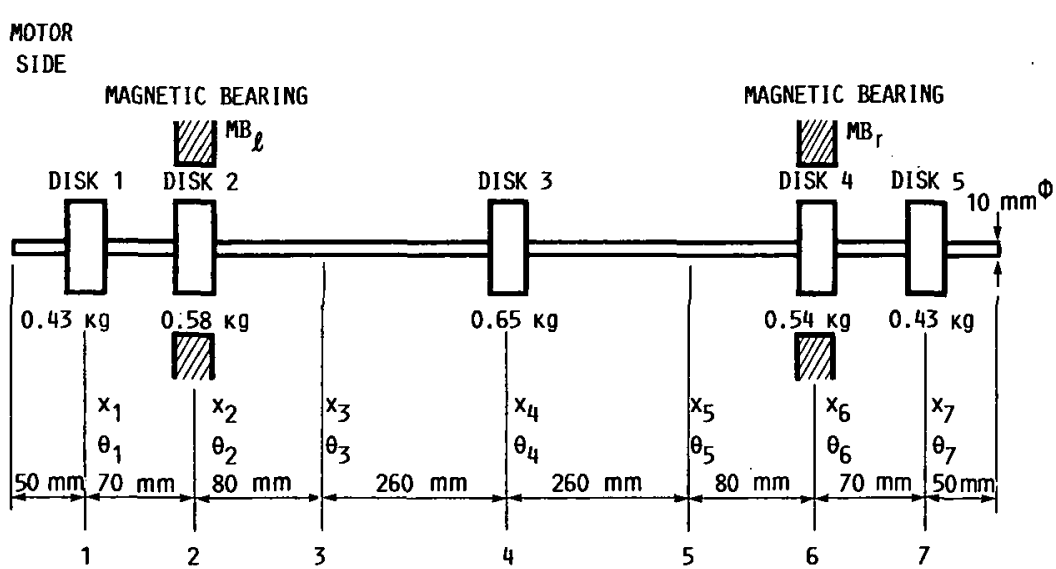

FI6. 2. - SCHEMATIC OF TEST ROTOR.

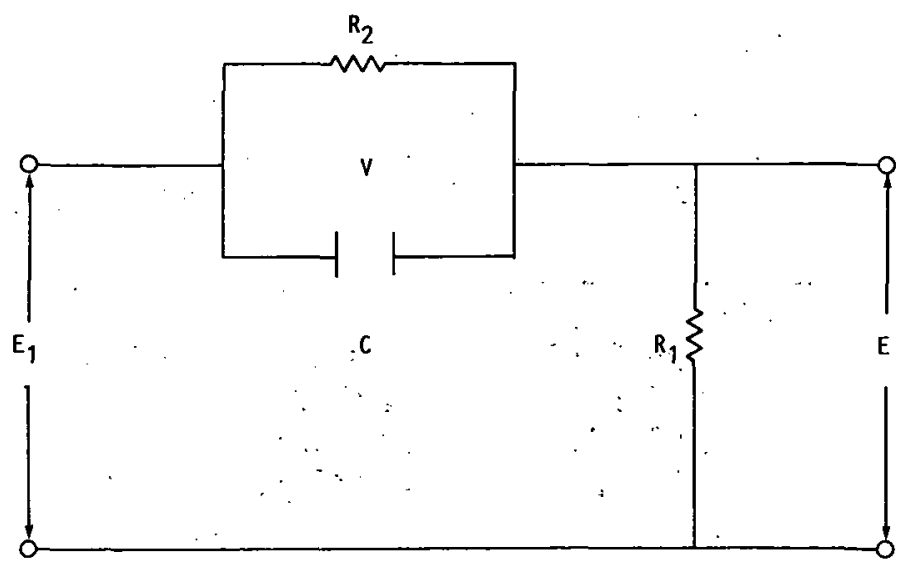

FI6. 3. - PHASE LEAD CIRCUIT. 


\section{ORIGINAI PAGE IS \\ OE POOR QUALITY}

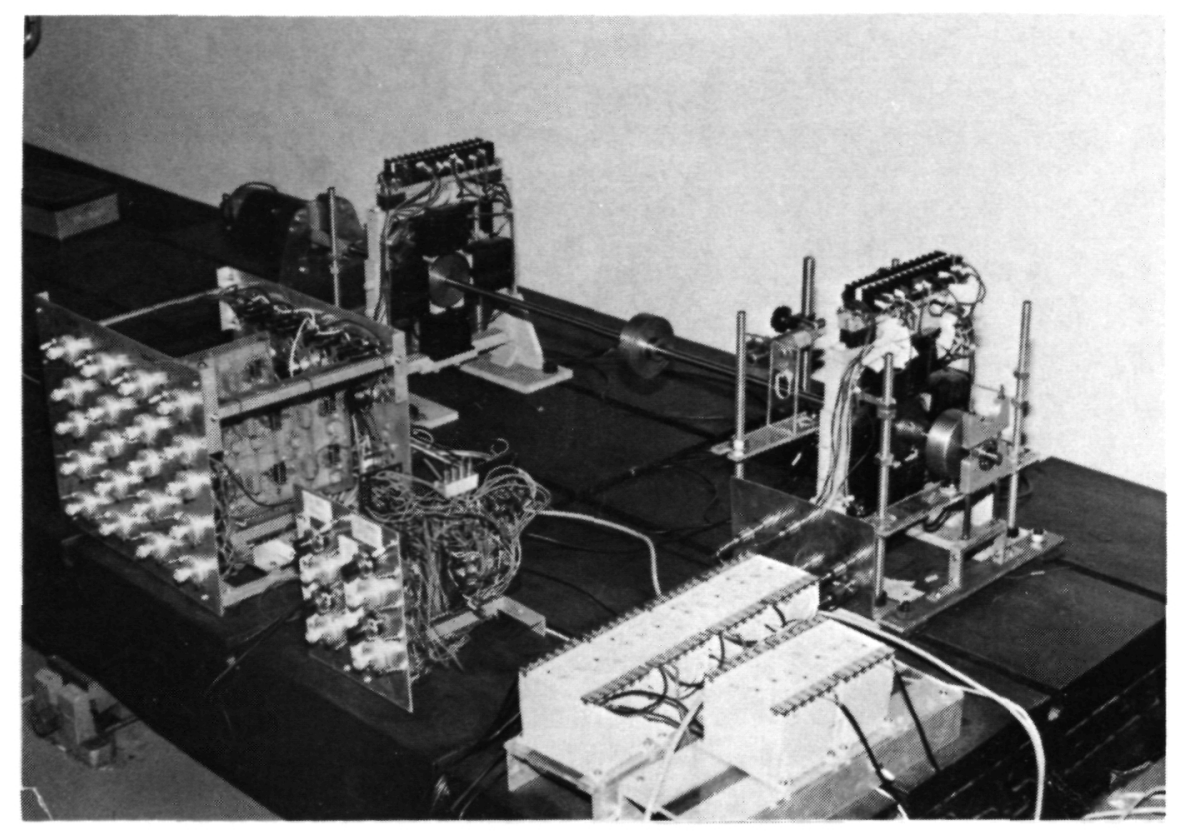

FIG. 4. - TEST RIG.

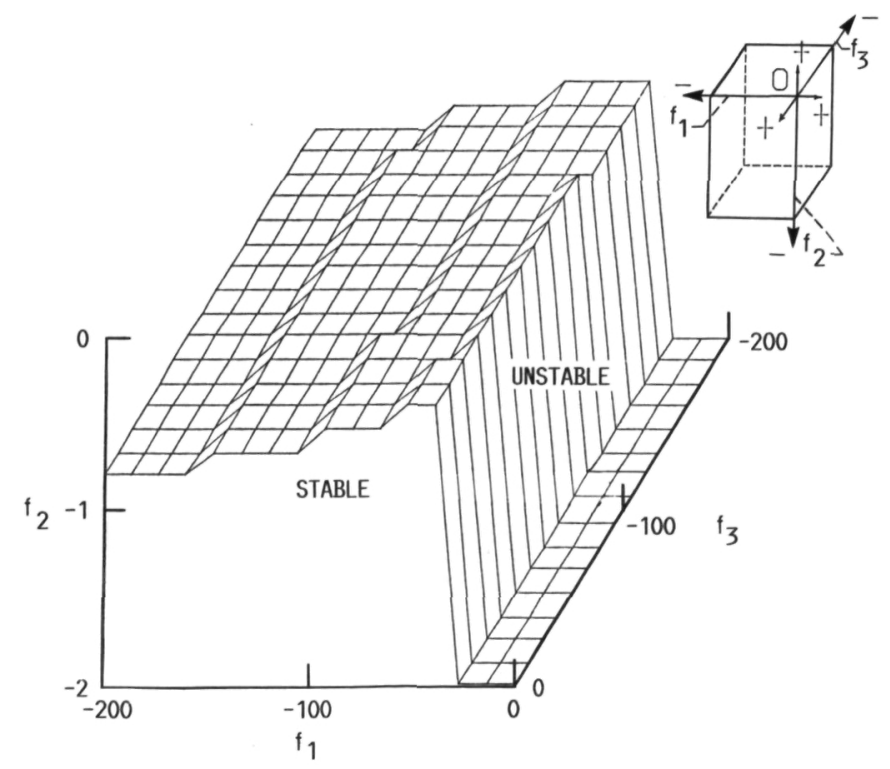

FIG. 5. - THREE-DIMENSIONAL STABILITY CRITERION CHART IN HORIZONTAL DIRECTION. 


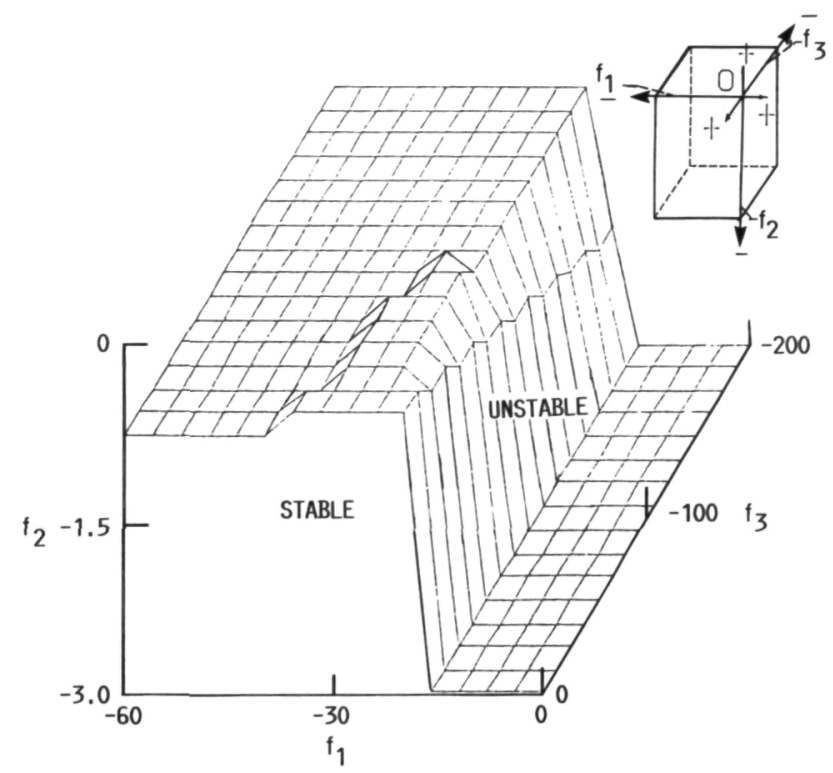

FIG. 6. - THREE-DIMENSIONAL STABILITY CRITERION CHART IN VERTICAL DIRECTION.

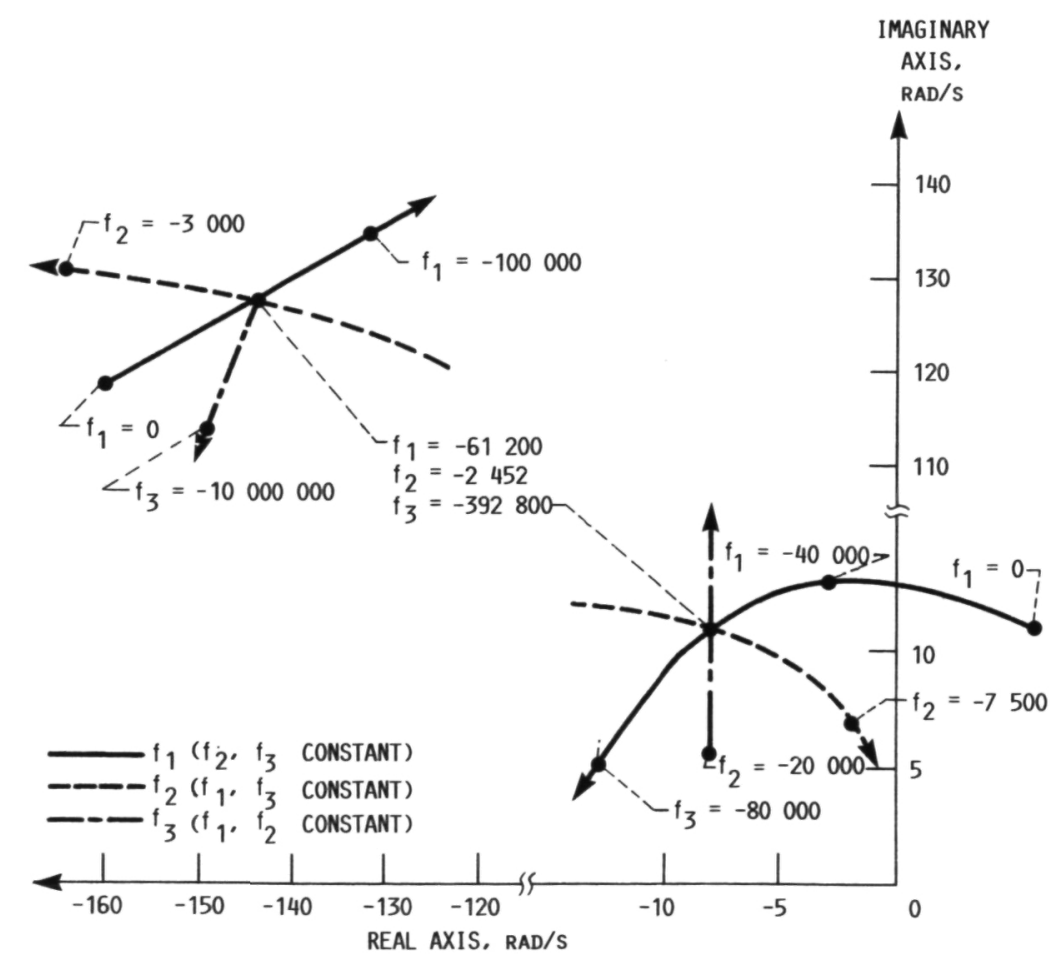

FIG. 7. - ROOT LOCI FOR DIFFERENT GAINS IN HORIZONTAL DIRECTION. 


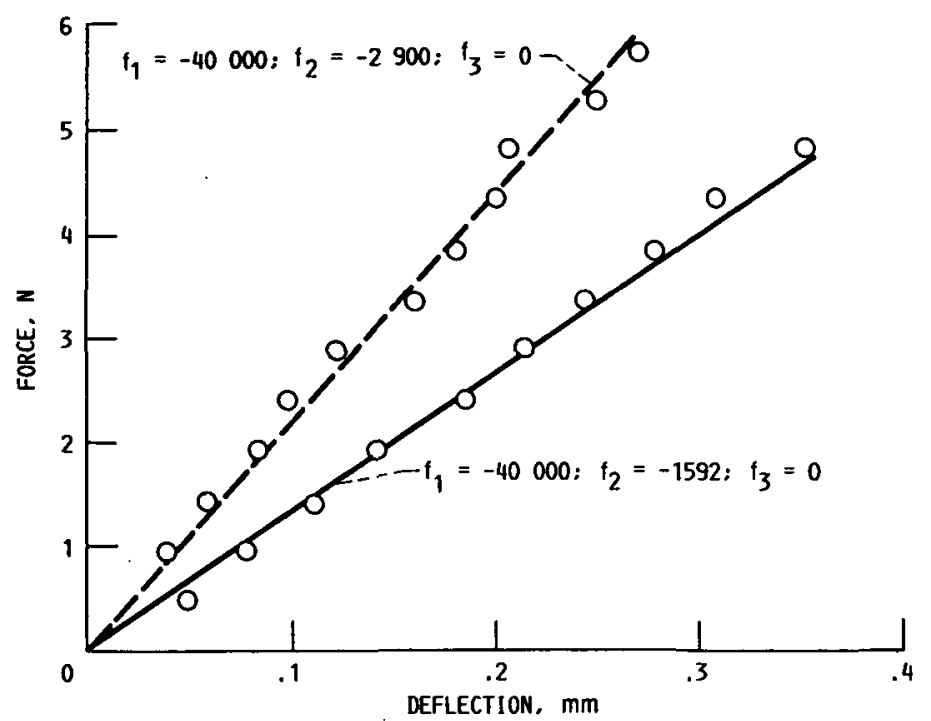

FIG. 8. - MEASURED STATIC SPRING CONSTANTS IN HORIZONTAL DIRECTION.

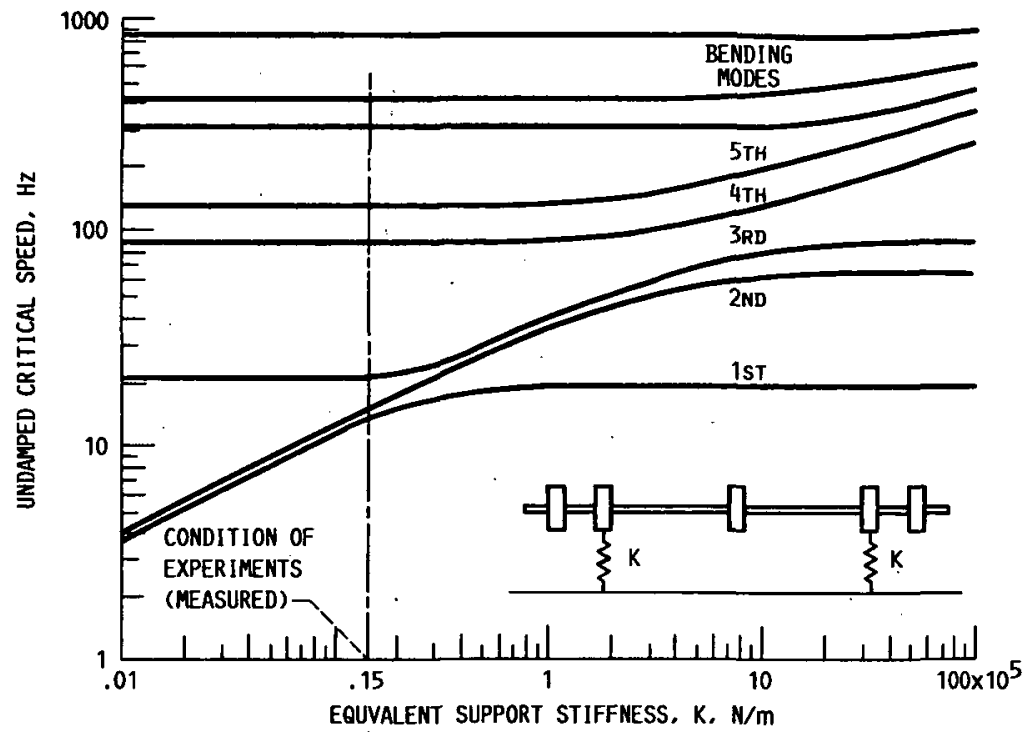

FIG. 9. - CRITICAL SPEED MAP OF THE ROTOR MODEL SHOWN IN FIG. 3.

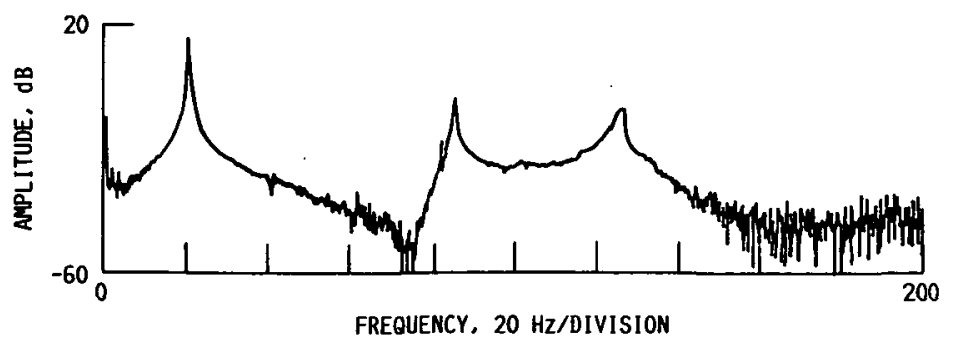

FIG. 10. - MEASURED FREE-FREE TEST DATA. 

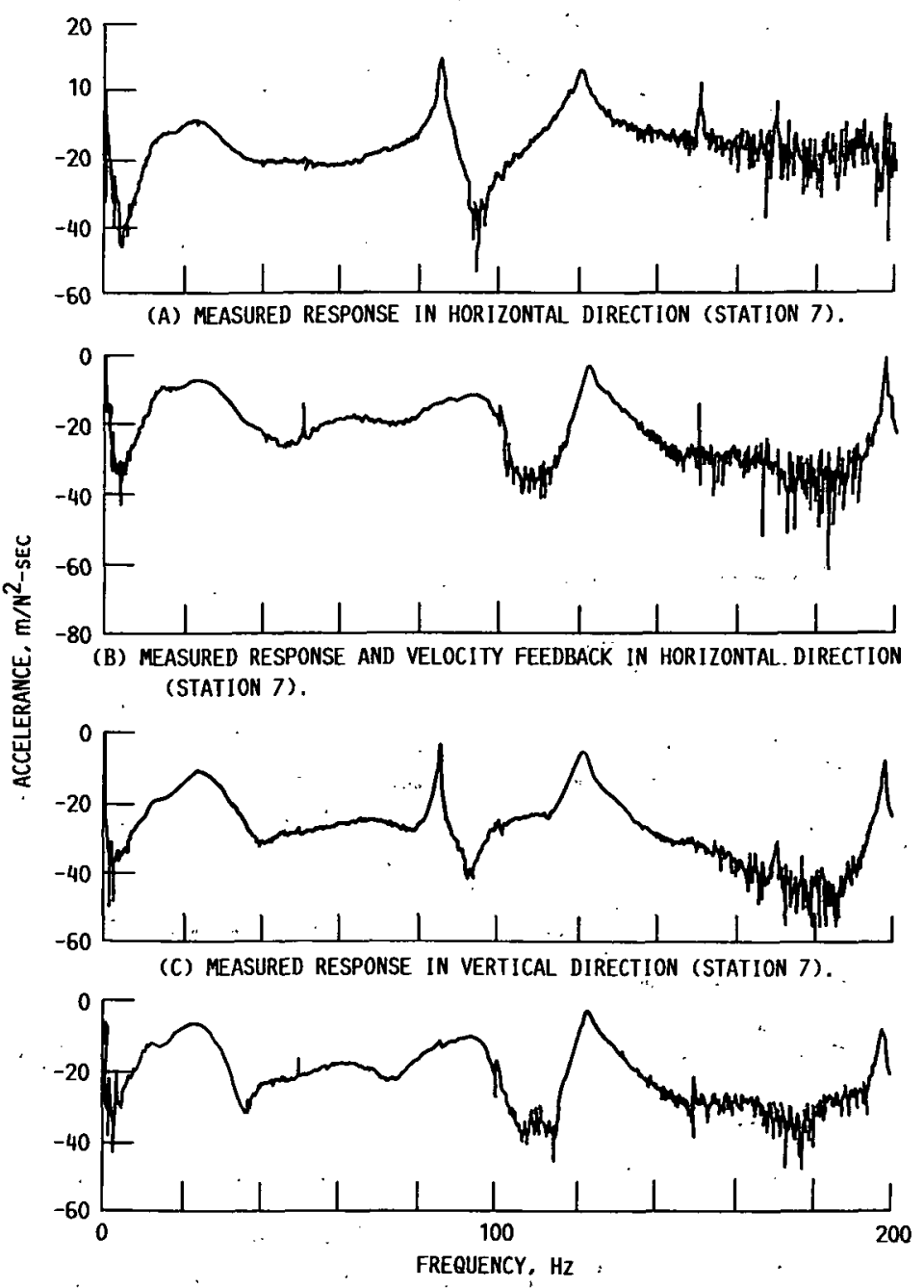

(D) MEASURED RESPONSE AND VELOCITY FEEDBACK IN VERTICAL DIRECTION (STATION 7).

FIG. 11. - MEASURED FREQUENCY, RESPOKSE. 
MODE FREQUEMCY,

2

Hz

12.48

$-----\ldots=13.42 x$
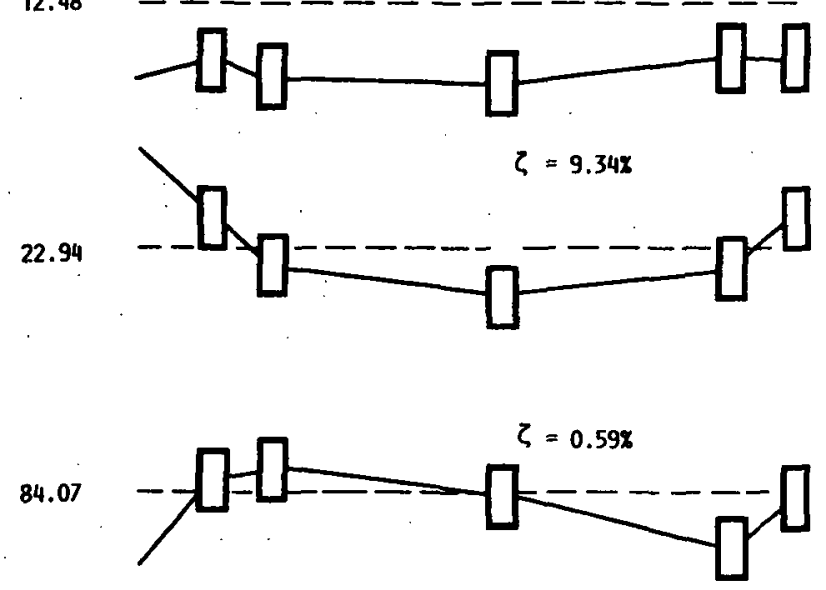

$\zeta=1.49 \%$

5

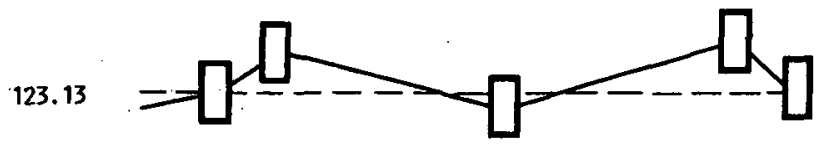

FIG. 12: - MEASURED MODE SHAPES AND MODAL DAMPIMG RATIOS. 


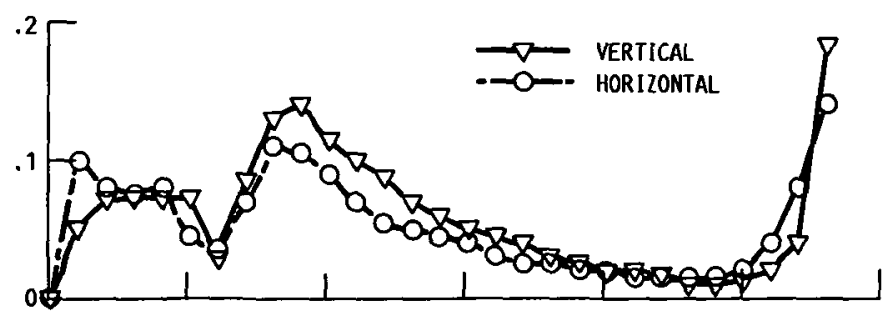

(A) DISK 1.
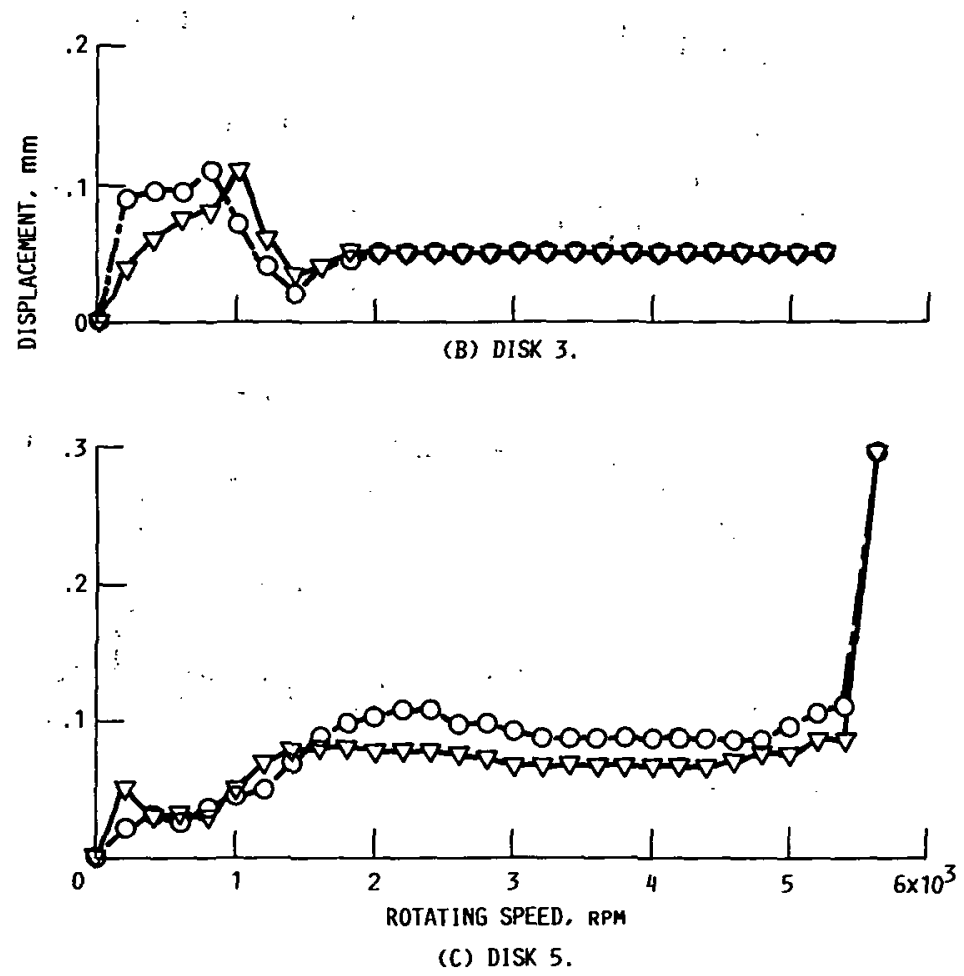

FIG. 13. - UNBALANCE RESPONSES. 


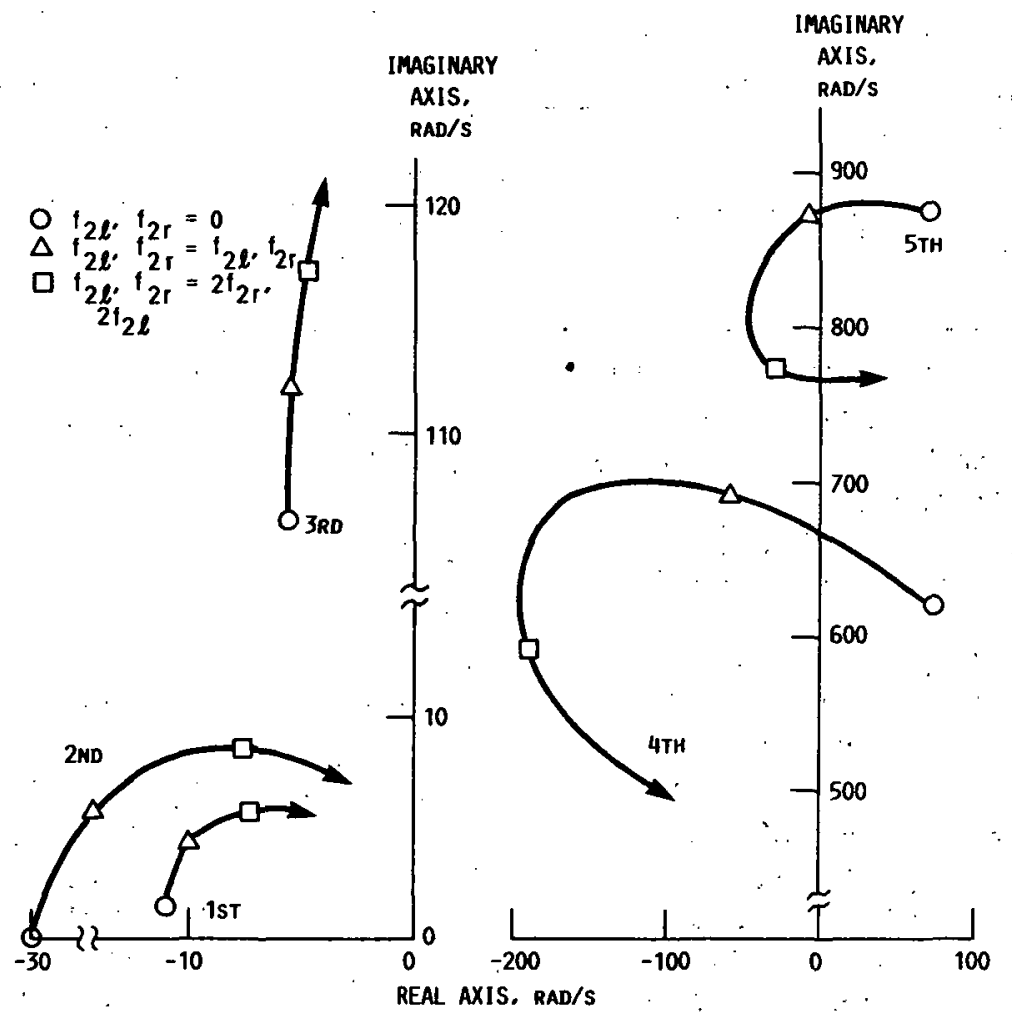

$\begin{array}{ll}\text { (A) MODES } 1 \text { TO } 3 . & \text { (B) MODES } 4 \text { AND } 5 .\end{array}$

FIG. 14. - ROOT LOCI HITHOUT COLLOCATION IN ADDITION TO VELOCITY FEEDBACK. 


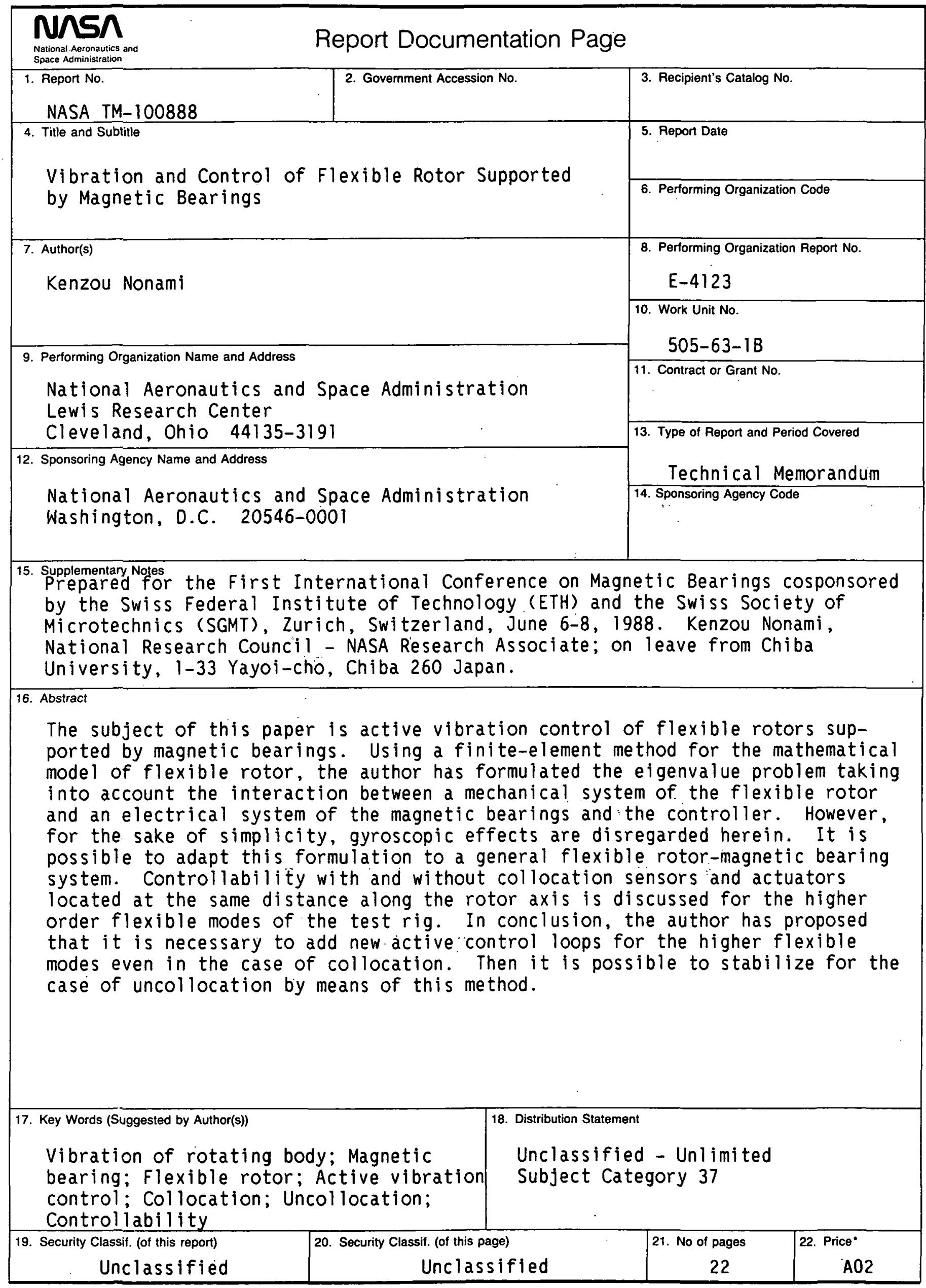

NASA FORM 1626 OCT $86 \quad$ *For sale by the National Technical Information Service, Springfield, Virginia 22161 
National Aeronautics and

Space Administration

Lewis Research Center

Cleveland, Ohio 44135

Otficlal Business

Penalty for Private Use $\$ 300$

FOURTH CLASS MAIL

ADDRESS CORRECTION REQUESTED
|||||

Postage and Fees Paid Natıonal Aeronautics and

Space Administration

NASA.45I 